\title{
Structural changes of nano-Pt particles during thermal ageing: Support-induced effect and related impact on the catalytic performances
}

\author{
J.P. Dacquin a , M. Cabié ${ }^{\mathrm{b}}$, C.R. Henry ${ }^{\mathrm{b}}$, C. Lancelot $^{\mathrm{a}}$, C. Dujardin ${ }^{\mathrm{a}}$, S.R. Raouf ${ }^{\mathrm{c}}$, P. Granger ${ }^{\mathrm{a}, *}$ \\ ${ }^{a}$ Unité de Catalyse et de Chimie du Solide UMR 8181, Université de Lille1, Bâtiment C3, 59655 Villeneuve d'Ascq, France \\ ${ }^{\mathrm{b}}$ Centre Interdisciplinaire de Nanoscience de Marseille, CNRS UPR 3118, Associated to Aix-Marseille Université, Campus Luminy, 13288 Marseille, France \\ ${ }^{\mathrm{c}}$ Khartoum University, College of Engineering, Chemical Engineering Department, P. Box 321, Khartoum, Sudan
}

\begin{abstract}
The simultaneous reduction of $\mathrm{NO}$ and $\mathrm{N}_{2} \mathrm{O}$ has been investigated on Pt-based catalysts supported on $\gamma$ $\mathrm{Al}_{2} \mathrm{O}_{3}$ and perovskite materials $\left(\mathrm{LaFeO}_{3}\right)$. Particular attention has been paid to the catalyst resistance to thermal sintering processes occurring under reaction conditions at elevated temperature in the presence of oxygen and water. Bulk and surface modifications have been examined using appropriate physicochemical techniques $\left(\mathrm{H}_{2}\right.$-TPR, XPS, and HRTEM) and have been tentatively correlated to the catalytic performances in terms of activity and selectivity. It has been found that a significant particle growth occurs on $4 \mathrm{wt} . \% \mathrm{Pt} / \gamma-\mathrm{Al}_{2} \mathrm{O}_{3}$ having a strong detrimental effect on the conversion of $\mathrm{N}_{2} \mathrm{O}$ at high temperature. On the other hand, $4 \mathrm{wt} . \% \mathrm{Pt} / \mathrm{LaFeO}_{3}$ exhibits a higher resistance to thermal sintering. Such a behaviour has been explained by the occurrence of strong metal/support interactions highlighted by high resolution TEM observations. The formation of epitaxially oriented Pt particles on the $\mathrm{LaFeO}_{3} \mathrm{Crys}-$ tal lattice during thermal activation, still observable after thermal ageing would partly explain the best resistance of $4 \mathrm{wt}$ \% $\mathrm{Pt} / \mathrm{LaFeO}_{3}$ to deactivation towards the conversion of $\mathrm{N}_{2} \mathrm{O}$ at high temperature. Hence, supported catalysts on $\mathrm{LaFeO}_{3}$ with lower Pt loading were prepared. It has been finally found a striking enhancement of the catalytic performances, opening a new practical interest for minimising the noble metal loading.
\end{abstract}

\section{Introduction}

Noble metal-modified perovskites have been recently developed for post-combustion applications particularly under threeway conditions [1]. In those typical cycling conditions, involving alternative reductive and oxidative atmospheres, reversible changes may occur at least at the surface with a partial reduction of $\mathrm{LaBO}_{3}$ (with $\mathrm{B}=\mathrm{Fe}, \mathrm{Co}$ ) into $\mathrm{La}_{2} \mathrm{O}_{3}$ and $\mathrm{BO}_{x}$ followed by the restoration of the structural properties of the perovskite [1-3]. The most important issue was presumably related to the consequences of those structural changes on the chemical environment and the oxidation state of noble metals. It was pointed out that noble metal cations, localised in B sites of the perovskite structure, might go out and segregate into metallic nanoparticles under rich conditions, whereas reverse oxidation/re-dispersion processes with partial inclusion of oxidic Pd species into the bulk perovskite would preferentially occur under lean atmosphere. Those transformations have been essentially characterised on $\mathrm{Pd} / \mathrm{LaCoO}_{3}$ and $\mathrm{Pd} / \mathrm{LaFe}_{x^{-}}$ $\mathrm{Co}_{1-x} \mathrm{O}_{3}$ [1-6] with the stabilization of oxidic palladium species in unusual oxidation states. It was found that those modifications

\footnotetext{
* Corresponding author. Fax: +33 320436561.

E-mail address: pascal.granger@univ-lille1.fr (P. Granger).
}

are activated at the surface at mild temperature $\left(T=300^{\circ} \mathrm{C}\right)$ and induce significant improvements on the catalytic performances (particularly the durability in three-way conditions) [1] because the particle growth of noble metals is inhibited under such conditions contrarily to usual observations on conventional alumina supports. As previously explained, the importance of those phenomena is mostly governed by the sensibility of perovskites under reductive atmosphere and, also, the sensibility of noble metals to oxidation under lean conditions. Recently, it was found that both aspects determine the extent of re-dispersion of Pd impregnated on $\mathrm{LaCoO}_{3}$. Pre-activation thermal treatments under successive reductive and oxidative atmospheres lead to significant re-dispersion of oxidic Pd species during the reconstruction of the perovskite structure [5-7]. Recently, similar tendencies have been reported on $\mathrm{Pt} / \mathrm{CeO}_{2}$ [8] with the formation of surface nanocomposite oxide that involves the formation of a Pt-O-Ce bond, which stabilises Pt against sintering and redisperses agglomerated Pt particles under oxidative conditions. Herein, we have examined the behaviour of Pt supported on $\mathrm{LaFeO}_{3}$ in terms of catalytic performances and resistance to particle sintering under reaction conditions. It will be found that the catalytic performance in the reduction of $\mathrm{NO}$ and $\mathrm{N}_{2} \mathrm{O}$ by hydrogen strongly depend on the pre-activation thermal treatment, which might originate different 
surface reconstruction phenomena as those earlier reported on Pd/ $\mathrm{LaCoO}_{3}$.

\section{Experimental}

\subsection{Catalyst preparation and characterisation}

The preparation procedure of $\mathrm{LaFeO}_{3}$ was described elsewhere $[9,10]$ using a so-called sol-gel method involving a citrate route. Iron and lanthanum nitrate salts were dissolved in the presence of citric acid (CA) according to the molar $\mathrm{CA} /(\mathrm{Fe}+\mathrm{La})$ ratio equal to 1 . The solvent was removed by heating at $60^{\circ} \mathrm{C}$ under vacuum until the formation of a gel. After drying at $80^{\circ} \mathrm{C}$, nitrates were decomposed at $200{ }^{\circ} \mathrm{C}$ before calcination in air at $600^{\circ} \mathrm{C}$ for $8 \mathrm{~h}$. $\mathrm{LaFeO}_{3}\left(25 \mathrm{~m}^{2} \mathrm{~g}^{-1}\right)$ and $\gamma-\mathrm{Al}_{2} \mathrm{O}_{3}\left(100 \mathrm{~m}^{2} \mathrm{~g}^{-1}\right)$ were impregnated by hexachloroplatinic acid solutions with adjusted concentrations in order to obtain $4 \mathrm{wt}$ \% Pt. The precursors thus obtained were calcined in air at $400{ }^{\circ} \mathrm{C}$ and successively reduced at $300{ }^{\circ} \mathrm{C}$ in $\mathrm{H}_{2}$ overnight. The samples were labelled, respectively, $4 \mathrm{Pt} / \mathrm{LaFe}(\mathrm{C} 400)$ and $4 \mathrm{Pt} / \mathrm{LaFe}(\mathrm{R} 300)$. The same nomenclature was adopted in the case of $\mathrm{Pt} / \gamma-\mathrm{Al}_{2} \mathrm{O}_{3}$. Subsequent comparisons were achieved with a reference $\mathrm{LaFe}_{0.95} \mathrm{Pt}_{0.05} \mathrm{O}_{3}$, in which Pt was directly introduced during the gel formation in order to obtain, after calcination at $600^{\circ} \mathrm{C}$, well-dispersed oxidic Pt species in the bulk structure of $\mathrm{LaFeO}_{3}$. The corresponding platinum loading was equal to $4 \mathrm{wt} . \%$. This reference sample was labelled $4 \mathrm{LaFePt}(\mathrm{C600})$. Thermal-ageing procedure was performed overnight, on reduced samples, under reactive conditions as described in Fig. 1. Aged catalysts were labelled 4Pt/ $\mathrm{LaFe}(\mathrm{A} 500)$ and $4 \mathrm{Pt} / \mathrm{Al}(\mathrm{A} 500)$. Hydrogen temperature-programmed reduction $\left(\mathrm{H}_{2}-\mathrm{TPR}\right)$ was carried out in a Micromeritics Autochem II 2920 apparatus (5 vol.\% $\mathrm{H}_{2} / \mathrm{Ar}$ ). X-ray photoelectron spectroscopy experiments (XPS) were performed using a Vacuum Generators Escalab 220XL spectrometer. A monochromatized aluminium source $(1486.6 \mathrm{eV})$ was used for excitation. Binding energy (BE) values were referenced to the binding energy of the $C 1 \mathrm{~s}$ core level $(285.1 \mathrm{eV})$. Simulation of the experimental photopeaks was carried out using a mixed Gaussian/Lorentzian peak fit procedure according to the software supplied by VG Scientific. Semi-quantitative analysis accounted for a nonlinear Shirley background subtraction $[11,12]$. Transmission electron microscopy (TEM) studies were performed on a Tecnai 20 microscope operating at an accelerating voltage of $200 \mathrm{kV}$, while high resolution TEM micrographs were recorded on a JEOL JEM-3010. Prior to TEM observations, samples were deposited from ethanolic solution onto holey-carbon copper grids.

\subsection{Catalytic measurements}

Temperature-programmed experiments were performed in a fixed-bed flow reactor using $0.7 \mathrm{~g}$ of pre-reduced catalysts in powder form. The total flow rate was $15 \mathrm{~L} \mathrm{~h}^{-1}$, corresponding to a gas hourly space velocity of approximately $10,000 \mathrm{~h}^{-1}$ calculated on the basis of the volume of the catalytic bed. The reactant mixture was typically composed of $1000 \mathrm{ppm} \mathrm{N}_{2} \mathrm{O}, 1000 \mathrm{ppm}$ NO, 3 vol.\% $\mathrm{O}_{2}, 0.5$ vol.\% $\mathrm{H}_{2} \mathrm{O}$ and 0.5 vol.\% $\mathrm{H}_{2}$ as reducing agent. Inlet and outlet gas mixtures were analysed with a $\mu \mathrm{GC}$ Varian CP-4900 chromatograph fitted with two thermal conductivity detectors and a Balzer mass spectrometer for the detection and the quantification of $\mathrm{NO}_{2}$. Prior to quantification, reactants and products were separated on two 5 - $\AA$ molecular sieve and poraplot $Q$ columns. The temperature was gradually increased during temperature-programmed experiments with a constant heating rate of $3{ }^{\circ} \mathrm{C} \mathrm{min}{ }^{-1}$. As shown in Fig. 1, as-prepared and aged catalysts were systematically pre-reduced in $\mathrm{H}_{2}$ at $300{ }^{\circ} \mathrm{C}$ before temperatureprogrammed reaction (TPR-1 and TPR-2).

\section{Results and discussion}

\subsection{Reducibility of oxidic Pt species dispersed on as-prepared and aged $\mathrm{Pt} / \mathrm{LaFeO}_{3}$}

The reducibility of $\mathrm{LaFeO}_{3}$ and $4 \mathrm{Pt} / \mathrm{LaFe}(\mathrm{C} 400)$ catalysts is illustrated in Fig. 2. $\mathrm{H}_{2}$-TPR experiments were also repeated on $4 \mathrm{Pt} / \mathrm{La}-$ $\mathrm{Fe}(\mathrm{A} 500)$ after thermal ageing. As exemplified, no significant hydrogen uptake is noticeable on $\mathrm{LaFeO}_{3}$. Parallel XPS and XRD measurements (results not shown) showed that $\mathrm{Fe}^{3+}$ remains unchanged inside the perovskite structure up to $700{ }^{\circ} \mathrm{C}$. Deviation of the TCD signal is noticeable in Fig. $2 \mathrm{~b}$ on $\mathrm{Pt} / \mathrm{LaFe}(\mathrm{C} 400)$ with a maximum at $128^{\circ} \mathrm{C} . \mathrm{H}_{2}$ consumption has been essentially ascribed to the reduction of oxidic Pt species. The calculation of the atomic $\mathrm{H} / \mathrm{Pt}$ ratio (3.8) indicates the preferential stabilisation of $\mathrm{PtO}_{2}$ species on $\mathrm{LaFeO}_{3}$ after calcination in air. $\mathrm{H}_{2}$-TPR experiments were also performed on $4 \mathrm{Pt} / \mathrm{Al}(\mathrm{C} 400)$ leading to a lower atomic $\mathrm{H} / \mathrm{Pt}$ ratio (3.0), which suggests a preferential stabilisation of $\mathrm{Pt}^{2+}$ as $\mathrm{PtO}$ contrary to $4 \mathrm{Pt} / \mathrm{LaFe}(\mathrm{C} 400)$. Similar experiment on $4 \mathrm{Pt} / \mathrm{LaFe}(\mathrm{A} 500)$, reported in Fig. 2c, shows a shift of the $\mathrm{H}_{2}$ consumption profile to

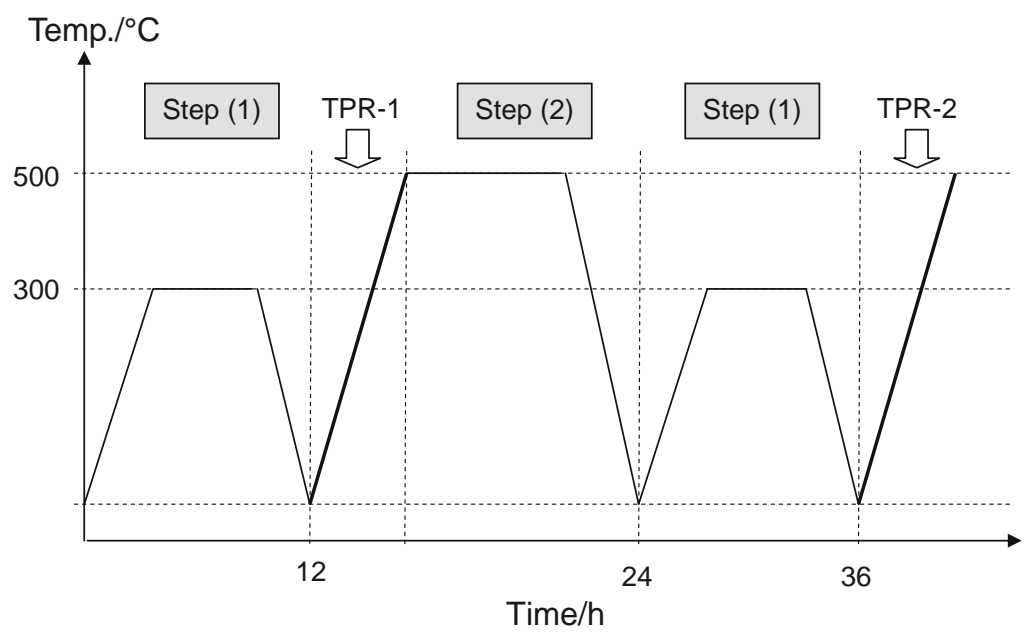

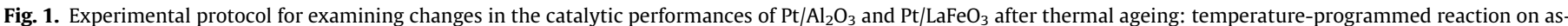

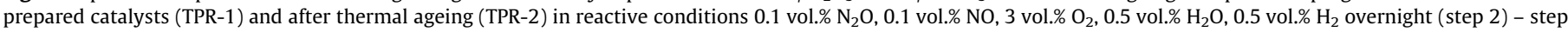
(1) reduction in pure hydrogen. 


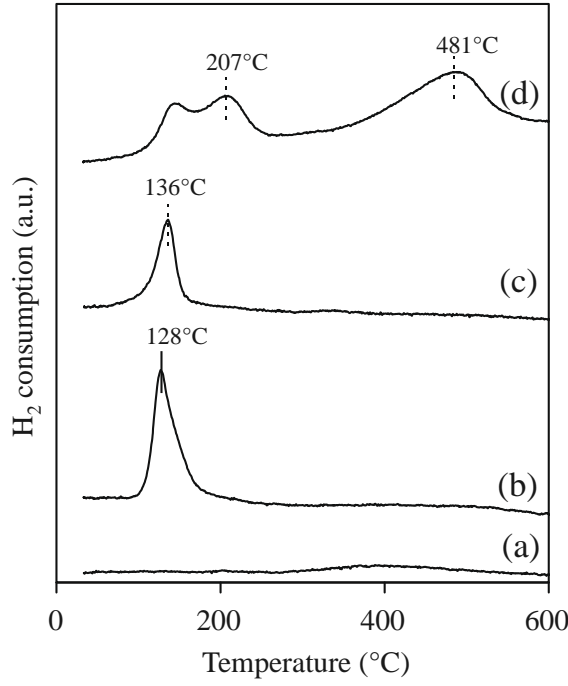

Fig. 2. $\mathrm{H}_{2}$-temperature-programmed reduction on $\mathrm{LaFeO}_{3}, 4 \mathrm{wt} . \% \mathrm{Pt} / \mathrm{LaFeO}_{3}$ and $\mathrm{LaFe}_{0.95} \mathrm{Pt}_{0.05} \mathrm{O}_{3}: \mathrm{LaFeO}_{3}$ (a); 4Pt/LaFe(C400) (b); aged 4Pt/LaFe(A500) (c); sol-gel $4 \mathrm{LaFePtO}_{3}(\mathrm{C} 600)(\mathrm{d})$. higher temperatures accompanied with a lower value for the atomic $\mathrm{H} / \mathrm{Pt}$ ratio (2.7). Such a variation may have different significances associated with an incomplete bulk re-oxidation of metallic Pt particles during thermal ageing under lean conditions, the formation of less reducible oxidic Pt species due to partial diffusion inside the bulk structure of $\mathrm{LaFeO}_{3}[5,6]$ and/or a preferential stabilisation of $\mathrm{Pt}^{2+}$ at the expense of $\mathrm{Pt}^{4+}$ as above-mentioned on alumina. It is worthwhile to note that the reference $4 \mathrm{LaFePt}(\mathrm{C600})$ behaves differently with the appearance of two $\mathrm{H}_{2}$ consumption domains characterised by maxima at 207 and $481{ }^{\circ} \mathrm{C}$, which largely exceed the theoretical $\mathrm{H}_{2}$ uptake needed for a complete reduction of $\mathrm{PtO}_{2}$ to $\mathrm{Pt}^{0}(\mathrm{H} / \mathrm{Pt}=13.6)$. Two comments may arise from these observations related to the fact that Pt inclusion in the perovskite structure drastically enhances its reducibility and the lack of observation of reduction processes at high temperature on $4 \mathrm{Pt} / \mathrm{LaFe}(\mathrm{A} 500)$ suggests that no significant diffusion of oxidic Pt species into the bulk structure of $\mathrm{LaFeO}_{3}$ occurs during thermal ageing.

\subsection{Transmission electronic microscopy (TEM) observations}

TEM images have been recorded on Pt supported on $\mathrm{Al}_{2} \mathrm{O}_{3}$ and on $\mathrm{LaFeO}_{3}$ and representative micrographs of the catalysts after different thermal treatments are reported in Figs. 3 and 4. Small

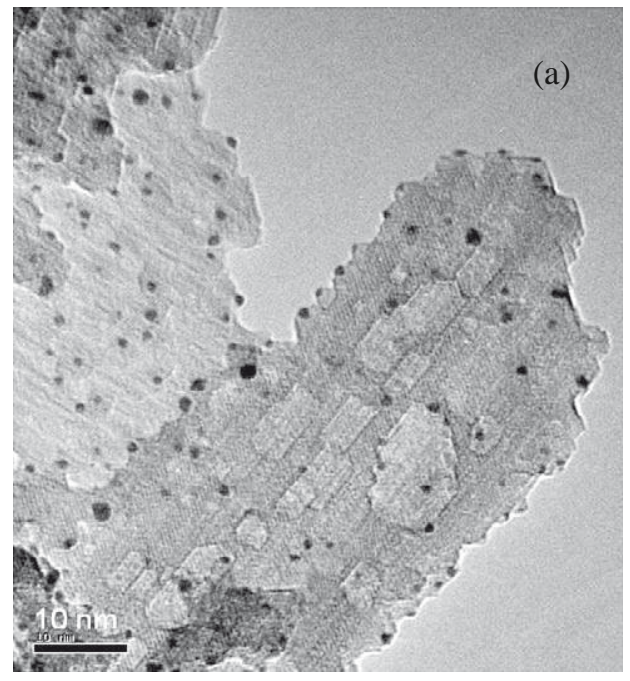

(c)

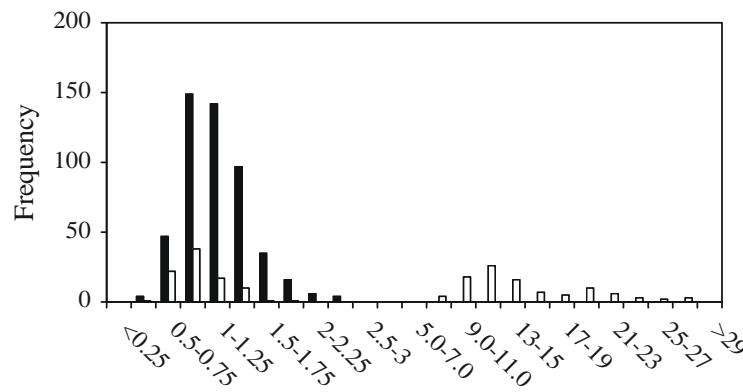

Particle Size $(\mathrm{nm})$

$\mathrm{R} 300 \mathbf{m}, \mathrm{A} 500 \mathrm{R} 300$ 口

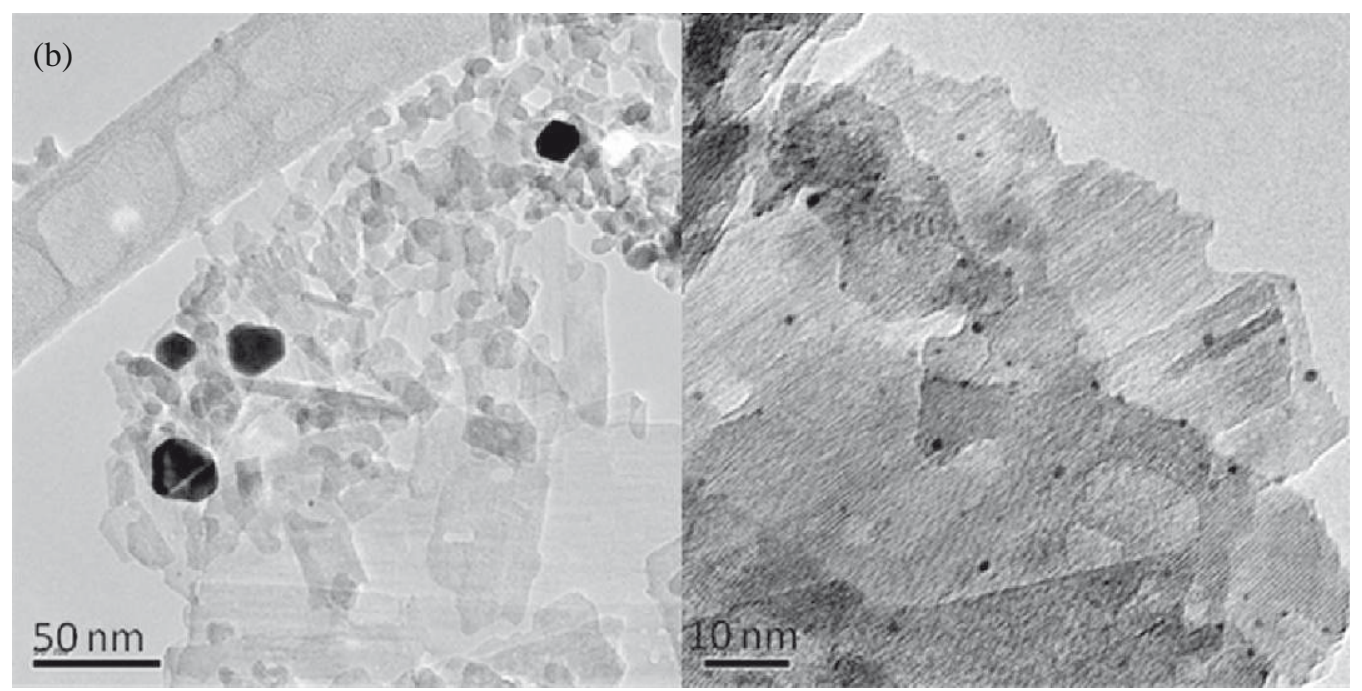

Fig. 3. TEM micrographs of an as-prepared $4 \mathrm{Pt} / \mathrm{Al}(\mathrm{R} 300)$ sample (a); of an aged $4 \mathrm{Pt} / \mathrm{Al}(\mathrm{A} 500 \mathrm{R} 300)$ sample (b). In (c), the particle size distributions of $4 \mathrm{Pt} / \mathrm{Al}(\mathrm{R} 300)$ ( $4 \mathrm{Pt} / \mathrm{Al}(\mathrm{A} 500 \mathrm{R} 300)(\square)$ samples are presented. For each histogram, 500 particles have been measured. 
metallic Pt particles are observable on 4Pt/Al(R300) in Fig. 3a with a mean diameter of $1.2 \mathrm{~nm}$ estimated from the particle size distribution (see Fig. 3c). Thermal ageing leads to drastic changes with the appearance of a bimodal distribution. The presence of metallic Pt particles, smaller than $1.5 \mathrm{~nm}$, is still observed on $4 \mathrm{Pt} /$ $\mathrm{Al}(\mathrm{A} 500 \mathrm{R} 300)$ with a mean particle size of $0.9 \mathrm{~nm}$. However, successive thermal treatments also lead to the formation of larger particles in the range $5-30 \mathrm{~nm}$, with a mean diameter of $15 \mathrm{~nm}$. TEM micrographs on $\mathrm{Pt} / \mathrm{LaFeO}_{3}$ in Fig. 4 reveal different information. The orthorhombic phase of $\mathrm{LaFeO}_{3}$ is observed and identified from measurements in HRTEM of the lattices fringes of the $(200)$, ( $\left.\begin{array}{lll}0 & 0 & 2\end{array}\right),\left(\begin{array}{lll}1 & 1 & 1\end{array}\right)$ and $\left(\begin{array}{lll}2 & 0 & 2\end{array}\right)$ crystal planes characteristic of this structure (respectively, $2.778 \AA$, $3.929 \AA$, $3.514 \AA ̊$ and $2.269 \AA$ ). However, heterogeneous spatial distribution of platinum particles is noticed on the perovskite support irrespective of the nature of the thermal treatment with areas without any particles, whereas other parts are densely populated with small Pt particles exhibiting a particle diameter smaller than $4 \mathrm{~nm}$ (Fig. $4 \mathrm{a}-\mathrm{c}$ ). Very few large particles with a diameter around $10-20 \mathrm{~nm}$ are also present. The lattice fringes measured on the different particles correspond to the (1 11 1) planes of metallic platinum, whatever the particle size and independently of the thermal treatment nature (oxidative or reductive atmosphere). Moreover, the particle size distributions from the different $4 \mathrm{wt}$.\% $\mathrm{Pt} / \mathrm{LaFO}_{3}$ samples (Fig. $4 \mathrm{~d}$ ) appear to be monomodal with mean particle sizes of $1.5 \mathrm{~nm}, 1.6 \mathrm{~nm}$ and $1.1 \mathrm{~nm}$ for, respectively, 4Pt/LaFe(R300), 4Pt/LaFe(A500) and 4Pt/
LaFe(A500R300), confirming that the platinum particles do not sinter during these successive thermal treatments. Furthermore, $4 \mathrm{Pt} /$ LaFe(A500R300) is characterised by a narrower size distribution with a mean size of $1.1 \mathrm{~nm}$ against $1.5 \mathrm{~nm}$ on $4 \mathrm{Pt} / \mathrm{LaFe}(\mathrm{R} 300)$, which may reflect the involvement of re-dispersion processes of Pt at the surface as previously demonstrated with Pd supported on $\mathrm{LaCoO}_{3}[5,6]$. It has been found that reconstruction phenomena are mainly governed by surface reduction/oxidation processes activated under successive reductive and oxidative atmospheres, respectively. As a result, partial incorporation of isolated oxidic Pd species in the bulk structure of $\mathrm{LaCoO}_{3}$ was previously observed after reconstruction [6,7]. Nevertheless, those processes were driven by significant structural changes, which have not been observed on $\mathrm{LaFeO}_{3}$ due to its weak reducibility. The highest strength of Pt particles than Pd to bulk oxidation illustrated from $\mathrm{H}_{2}$-TPR experiments, in agreement with TEM observations, would also inhibit those possible structural modifications. As seen in Fig. 4b, clear identification of Pt particles from the contrast with the support can be achieved on 4Pt/LaFe(A500), which underlines that even under oxidative conditions and at high temperature, the metallic character of Pt would be preserved, oxidation processes being strictly limited to the first layers of metallic Pt particles. In order to get a better understanding of this behaviour, particular attention has been paid to possible interactions of $\mathrm{Pt}$ particles with the support. Among the observed particles, HRTEM micrographs recorded on $4 \mathrm{Pt} / \mathrm{LaFe}$ (R300) show a preferential

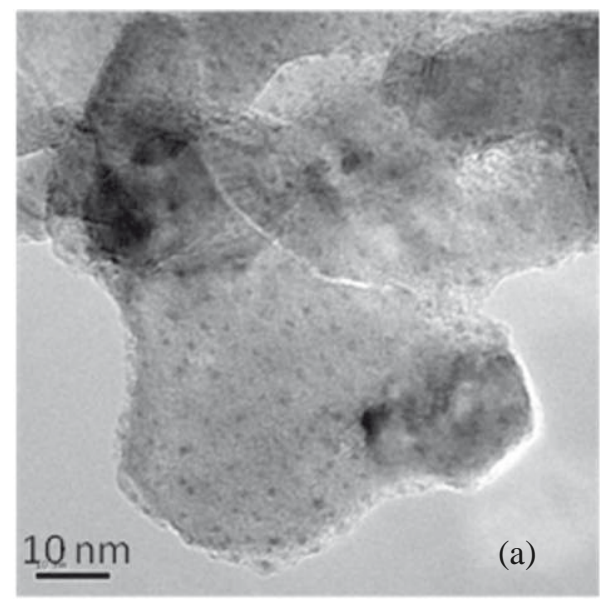

(d)
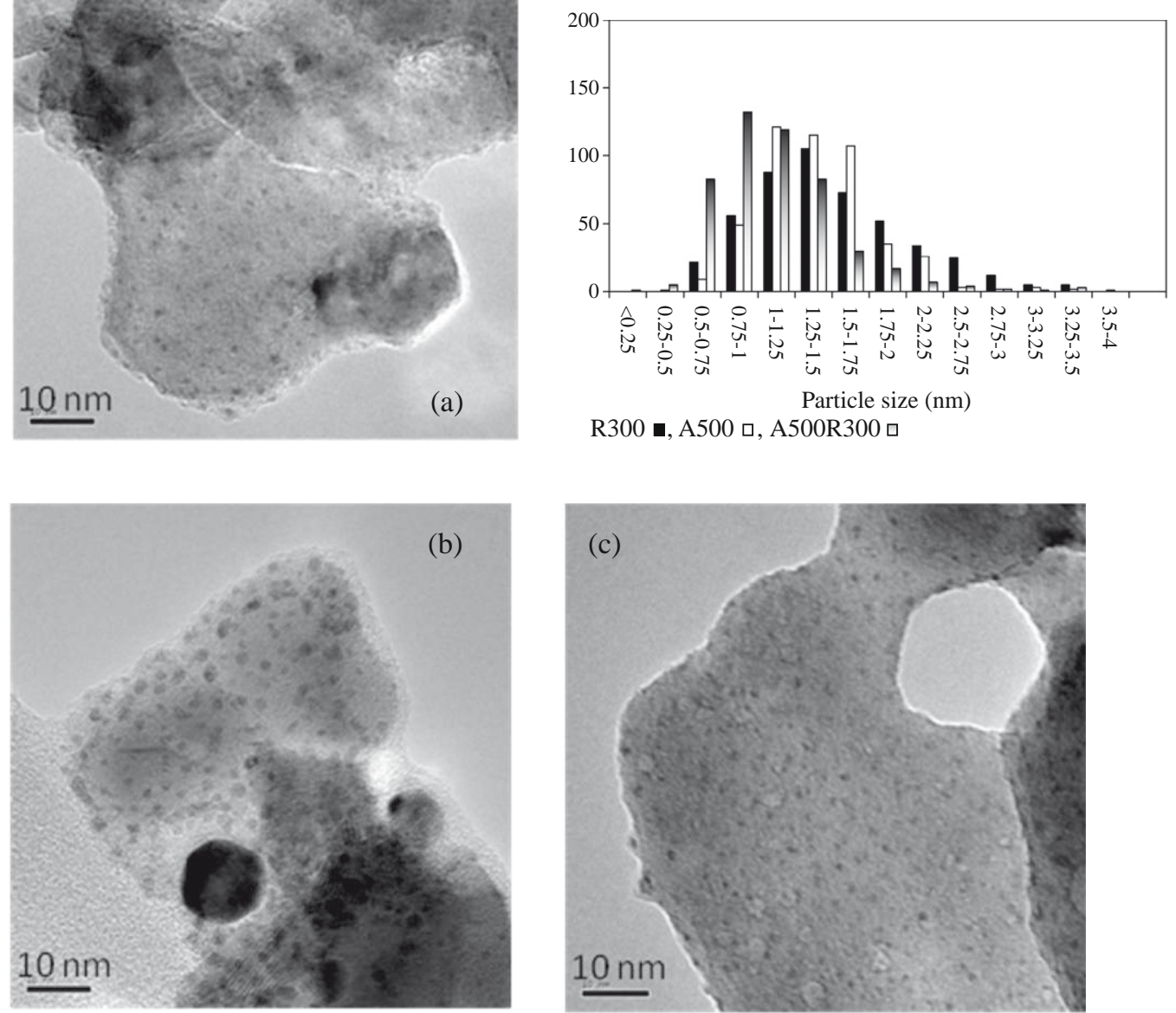

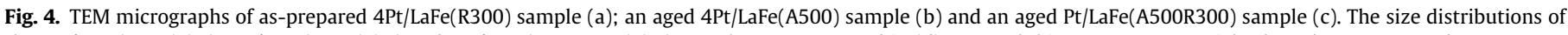
the 4Pt/LaFe(R300) (ם), 4Pt/LaFe(A500) ( $\square$ ) and 4Pt/LaFe(A500R300) ( $\square$ ) samples are presented in (d). For each histogram, 500 particles have been measured. 

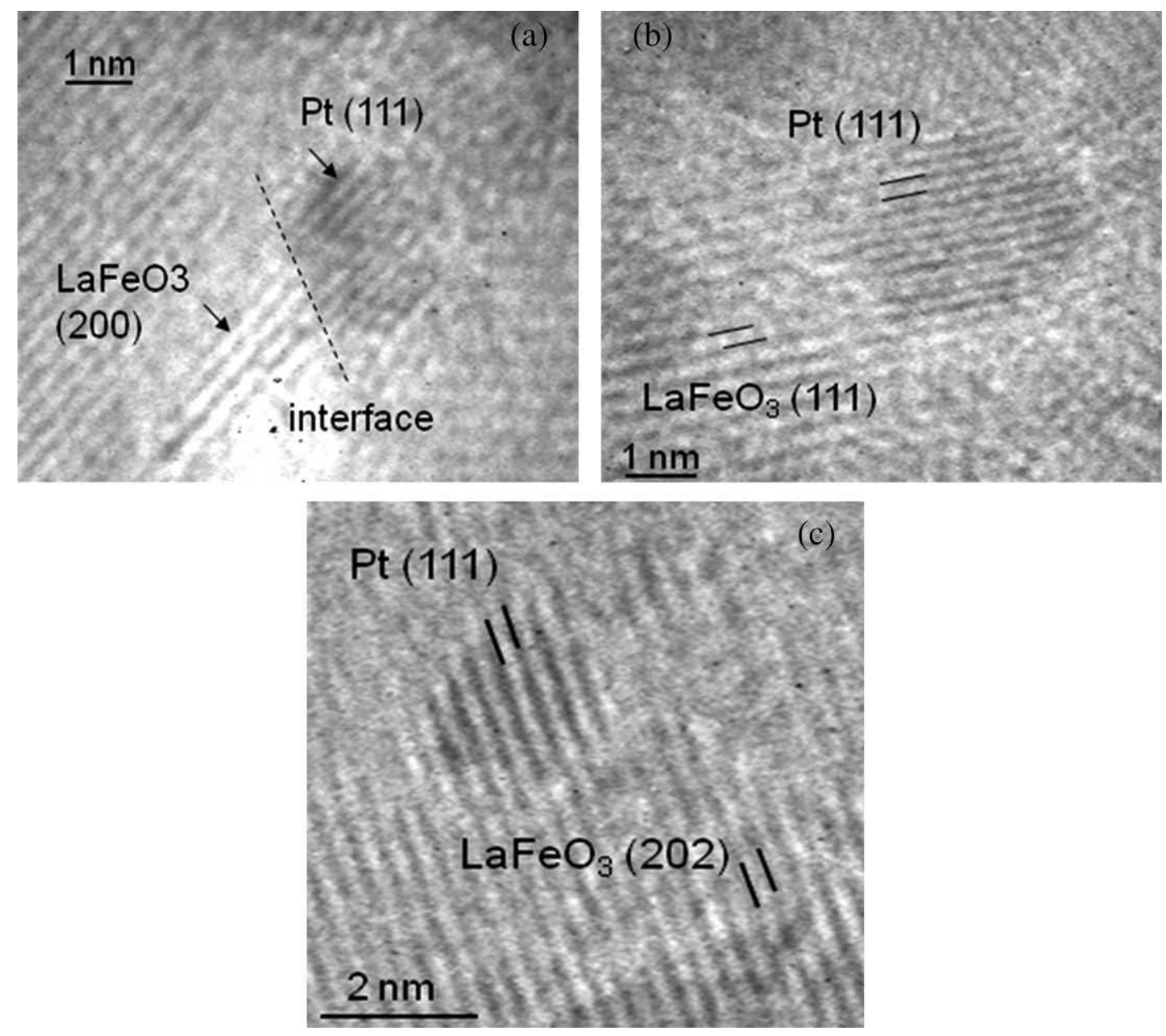

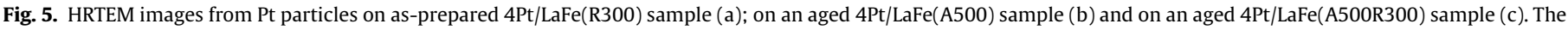

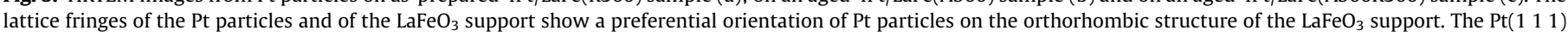
crystal planes tend to be parallel to the low index lattice planes of the $\mathrm{LaFeO}_{3}$ structure.

orientation of the (1 111$)$ crystal planes of the Pt particles parallel to the different low index (2 $\left.\begin{array}{lll}2 & 0\end{array}\right),\left(\begin{array}{lll}1 & 1 & 1\end{array}\right),\left(\begin{array}{lll}0 & 0 & 2\end{array}\right)$ and (2 $\left.\begin{array}{lll}2 & 2\end{array}\right)$ planes characteristic of $\mathrm{LaFeO}_{3}$ orthorhombic structure (see Fig. 5). Similar observations were repeated on $4 \mathrm{Pt} / \mathrm{LaFe}(\mathrm{A} 500)$ and $4 \mathrm{Pt} / \mathrm{La}-$ $\mathrm{Fe}(\mathrm{A500R300)}$, which emphasise the fact that these small metallic Pt particles strongly interact with the support even after subsequent thermal treatments. These preferential orientations towards the support would be able to protect them from thermal sintering processes under lean conditions.

\subsection{Surface analysis by XPS and correlation with $\mathrm{H}_{2}$-TPR and TEM observations}

XPS analysis was performed in order to compare the characteristic BE values of metallic and oxidic Pt species according to the nature of the support and the thermal treatments. Pt 4d photopeak instead of Pt $4 \mathrm{f}$ core level was examined on $\mathrm{Pt} / \mathrm{Al}_{2} \mathrm{O}_{3}$ due to the overlapping between $\mathrm{Pt} 4 \mathrm{f}$ and $\mathrm{Al} 2 \mathrm{p}$ photopeaks. Pt $4 \mathrm{~d}$ spectra on $4 \mathrm{Pt} / \mathrm{Al}(\mathrm{C} 400), 4 \mathrm{Pt} / \mathrm{Al}(\mathrm{R} 300)$ and $4 \mathrm{Pt} / \mathrm{Al}(\mathrm{A} 500 \mathrm{R} 300)$ and $\mathrm{BE}$ values are reported in Fig. 6 and Table 1, respectively. All characterised the preferential stabilization of $\mathrm{Pt}^{2+}$ possibly as $\mathrm{PtO}$ on $4 \mathrm{Pt} /$ $\mathrm{Al}(\mathrm{A} 300)$ according to literature data reported elsewhere [13]. Comparable $\mathrm{BE}$ values characterise $4 \mathrm{Pt} / \mathrm{Al}(\mathrm{R} 300)$ and $4 \mathrm{Pt} /$ $\mathrm{Al}(\mathrm{A500R300)}$, which can be ascribed to the presence of metallic Pt species covered by chemisorbed $\mathrm{O}$ atoms due to storage in ambient atmosphere after reduction. The most important observations are probably related to a significant decrease in the surface atomic
$\mathrm{Pt} / \mathrm{Al}$ ratio from 0.13 to 0.05 after thermal ageing associated to particle sintering in accordance with TEM observations reported in Fig. 3. As illustrated in Fig. 7, particular attention has been paid towards the Pt $4 \mathrm{f}$ core level on $4 \mathrm{Pt} / \mathrm{LaFeO}_{3}$. Pt $4 \mathrm{f} \mathrm{7/2}$ photopeak recorded on $4 \mathrm{Pt} / \mathrm{LaFe}(\mathrm{C} 400)$ in Fig. $7 \mathrm{a}$ is characterised by a main

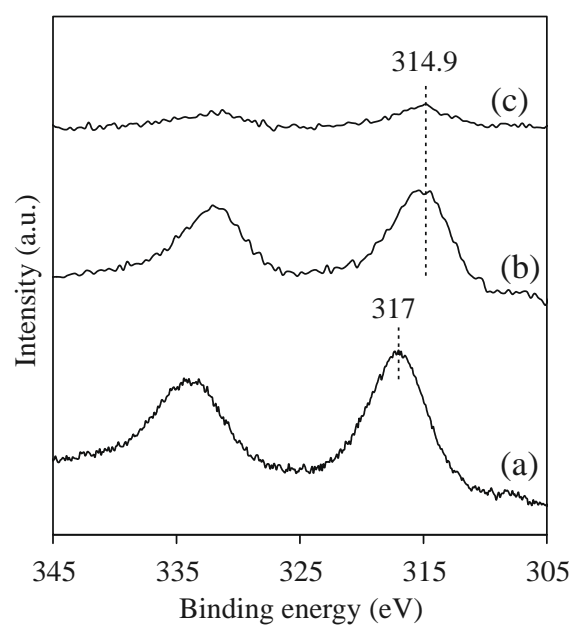

Fig. 6. XPS Spectra of Pt $4 \mathrm{~d}$ on 4 wt.\% $\mathrm{Pt} / \mathrm{Al}_{2} \mathrm{O}_{3}$ : $4 \mathrm{Pt} / \mathrm{Al}(\mathrm{C} 400)$ (a), $4 \mathrm{Pt} / \mathrm{Al}(\mathrm{R} 300)$ (b), and $4 \mathrm{Pt} / \mathrm{Al}(\mathrm{A} 500 \mathrm{R} 300)(\mathrm{c})$ 
Table 1

XPS analysis of $\mathrm{Pt} / \mathrm{Al}_{2} \mathrm{O}_{3}$ and $\mathrm{Pt} / \mathrm{LaCoO}_{3}$ after exposure under oxidative and reductive conditions.

\begin{tabular}{|c|c|c|c|c|c|c|c|c|}
\hline \multirow[t]{2}{*}{ Catalysts } & \multicolumn{2}{|l|}{$\mathrm{BE}(\mathrm{eV})$} & \multicolumn{3}{|c|}{ Surface composition $^{\mathrm{b}}$} & \multirow{2}{*}{$\begin{array}{l}\text { Bulk composition } \\
\mathrm{Pt} / \mathrm{M}(\mathrm{M}=\mathrm{Al} \text { or } \mathrm{La})\end{array}$} & \multirow[t]{2}{*}{$\mathrm{H}_{2}$ uptake $^{\mathrm{a}}\left(\mu \mathrm{mol} \mathrm{g}{ }^{-1}\right.$ catal.) } & \multirow[t]{2}{*}{$\mathrm{H} / \mathrm{Pt}^{\mathrm{a}}$} \\
\hline & Pt $4 d 5 / 2$ & Pt $4 f 7 / 2$ & $\mathrm{Pt} / \mathrm{Al}$ & $\mathrm{Pt} / \mathrm{La}$ & $\mathrm{Fe} / \mathrm{La}$ & & & \\
\hline $4 \mathrm{Pt} / \mathrm{Al}(\mathrm{C} 400)$ & 317.0 & & 0.018 & & & 0.011 & 309 & 3.0 \\
\hline 4Pt/Al(R300) & 314.9 & & 0.013 & & & & & \\
\hline 4Pt/Al(A500R300) & 314.9 & & 0.005 & & & & & \\
\hline $4 \mathrm{Pt} / \mathrm{LaFe}(\mathrm{C} 400)$ & & 75.0 & & 0.15 & 0.80 & 0.052 & 393 & 3.8 \\
\hline 4Pt/LaFe(R300) & & 72.5 & & 0.10 & 0.82 & & & \\
\hline 4Pt/LaFe(A500R300) & & 72.1 & & 0.11 & 0.78 & & & \\
\hline 4LaFePt(C600) & & 74.5 & & 0.097 & 0.56 & 0.052 & 1399 & 13.6 \\
\hline $0.5 \mathrm{Pt} / \mathrm{LaFe}(\mathrm{C} 400)$ & & 74.7 & & 0.032 & 0.74 & 0.006 & 52 & 4.1 \\
\hline $0.5 \mathrm{Pt} / \mathrm{LaFe}(\mathrm{R} 300)$ & & 72.5 & & 0.030 & 0.70 & & & \\
\hline 0.5Pt/LaFe(A500R300) & & 72.0 & & 0.027 & 0.78 & & & \\
\hline
\end{tabular}

a Calculated from $\mathrm{H}_{2}$-TPR experiments.

b Relative accuracy $\pm 20 \%$.

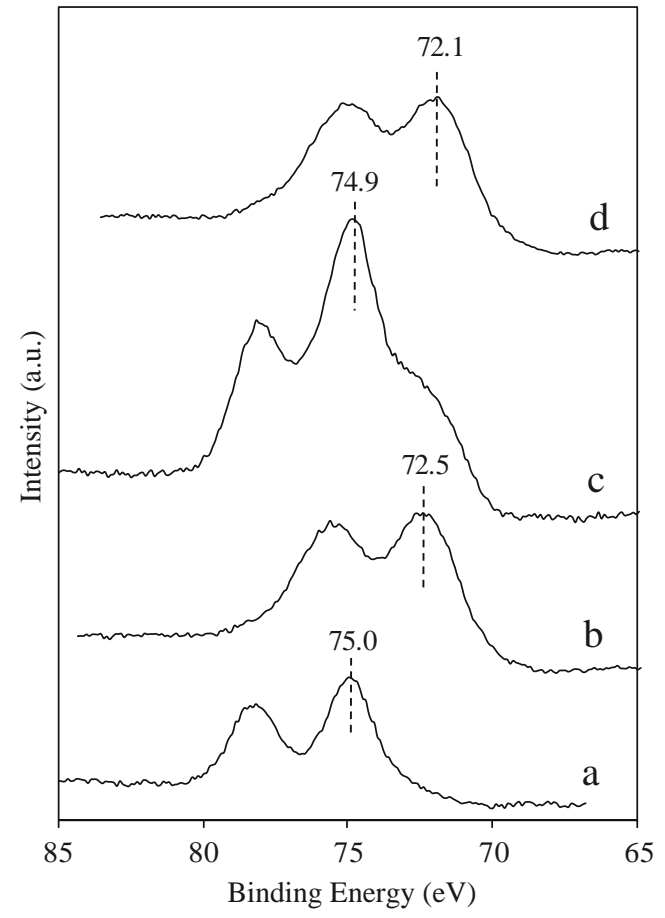

Fig. 7. XPS spectra of Pt $4 \mathrm{f}$ on 4 wt.\% Pt/LaFeO 3 : $4 \mathrm{Pt} / \mathrm{LaFe}(\mathrm{C} 400)$ (a), $4 \mathrm{Pt} / \mathrm{LaFe}(\mathrm{R} 300)$ (b), 4Pt/LaFe(A500) (c), and 4Pt/LaFe(A500R300) (d).

contribution on the overall spectrum at $75.0 \mathrm{eV}$ corresponding to the characteristic binding energy of $\mathrm{Pt}^{4+}$ in $\mathrm{PtO}_{2}$ [13]. Let us notice that those spectral features support $\mathrm{H}_{2}$-TPR measurements with the preferential stabilisation of $\mathrm{Pt}^{2+}$ on alumina whereas $\mathrm{Pt}^{4+}$ predominates on $4 \mathrm{Pt} / \mathrm{LaFe}(\mathrm{C} 400)$ coexisting with $\mathrm{Pt}^{2+}$ in significant lower concentration. Now, regarding 4Pt/LaFe(R300), a shift of the Pt $4 \mathrm{f} 7 / 2$ photopeak to lower BE values at $72.5 \mathrm{eV}$ reflects an extensive reduction of oxidic Pt species into metallic Pt particles in agreement with $\mathrm{H}_{2}$-TPR, which characterised a complete reduction of oxidic Pt species in those temperature conditions. Nevertheless, the corresponding $\mathrm{BE}$ value is higher than the usual value listed in the literature for $\mathrm{Pt}^{0}(71.0 \mathrm{eV}$ [13]), which may suggest the existence of peculiar interactions between $\mathrm{Pt}^{0}$ and $\mathrm{LaFeO}_{3}$ and/or disturbance on the electronic properties of Pt due to the electron withdrawing effect from chemisorbed hydroxyl groups and/or $\mathrm{O}$ atoms on $\mathrm{Pt}^{0}$ after exposure in air [13]. Let us now examine XPS measurements on $4 \mathrm{Pt} / \mathrm{LaFe}(\mathrm{A} 500)$ after exposure overnight at $500{ }^{\circ} \mathrm{C}$ under reactive mixture (spectrum c) and on $4 \mathrm{Pt} / \mathrm{La}-$ $\mathrm{Fe}(\mathrm{A500R} 300$ ) (spectrum d). In the former case, thermal ageing in lean conditions in the presence of $\mathrm{O}_{2}$ excess leads to the development of a major contribution at $74.9 \mathrm{eV}$, in line with the value obtained on $4 \mathrm{Pt} / \mathrm{LaFe}(\mathrm{C} 400)$. Parallel to that observation, a minor contribution is discernible at $72.5 \mathrm{eV}$ as previously discussed and representative of metallic $\mathrm{Pt}^{0}$ covered by $\mathrm{O}$ atoms and/or the stabilisation of PtO film at the topmost surface. This emphasises the fact that an extensive surface re-oxidation takes place but a complete re-oxidation seems to be ruled out in agreement with $\mathrm{H}_{2}$-TPR and TEM observations. Subsequent reduction in $\mathrm{H}_{2}$ leads to the restoration of the metallic character of Pt. Worth noting that a slightly lower $\mathrm{BE}$ value at $72.1 \mathrm{eV}$ is observed in comparison with that

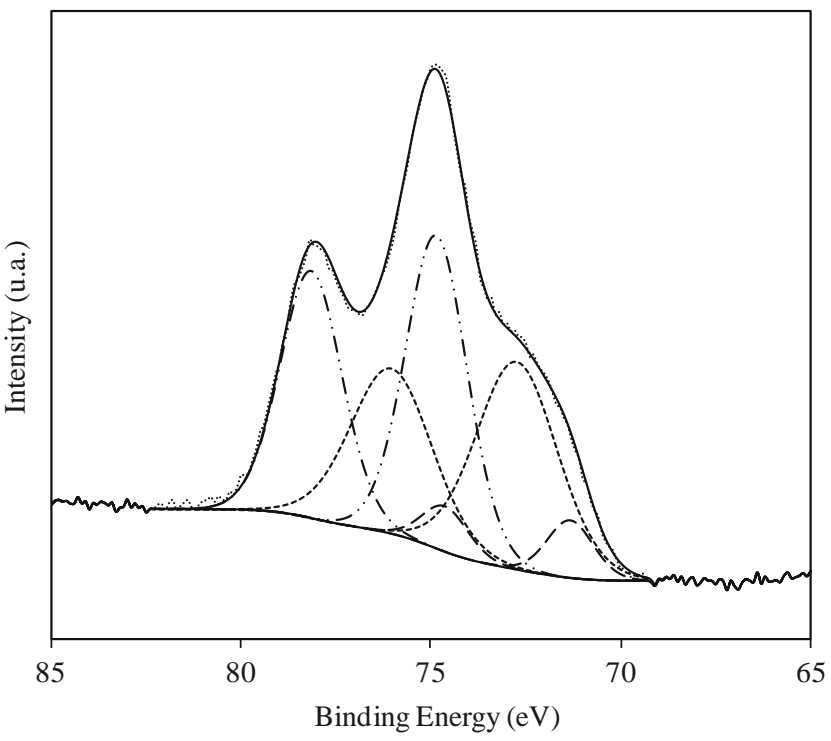

Fig. 8. Decomposition of the XPS Pt 4f photopeak recorded on 4Pt/LaFe(A500).

Table 2

Estimation of the relative surface composition of oxidic Pt species stabilised in different oxidation states.

\begin{tabular}{|c|c|c|c|c|c|}
\hline \multirow[t]{2}{*}{ Catalysts } & \multicolumn{3}{|c|}{ Relative surface composition } & \multirow[t]{2}{*}{$\mathrm{H} / \mathrm{Pt}^{\mathrm{a}}$} & \multirow[t]{2}{*}{$\mathrm{H} / \mathrm{Pt}^{\mathrm{b}}$} \\
\hline & $\mathrm{Pt}^{0}$ & $\mathrm{Pt}^{2+}$ & $\mathrm{Pt}^{4+}$ & & \\
\hline 4Pt/LaFe(C400) & 0 & 0.15 & 0.85 & 3.8 & 3.8 \\
\hline $4 \mathrm{Pt} / \mathrm{LaFe}(\mathrm{R} 300)$ & 0.09 & 0.80 & 0.11 & & \\
\hline 4Pt/LaFe(A500) & 0.07 & 0.44 & 0.49 & 2.7 & 2.7 \\
\hline $4 \mathrm{Pt} / \mathrm{LaFe}(\mathrm{A} 500 \mathrm{R} 300)$ & 0.07 & 0.88 & 0.05 & & \\
\hline
\end{tabular}

a Estimated from the relative concentration of $\mathrm{Pt}^{4+}, \mathrm{Pt}^{2+}$ from deconvoluted XPS spectra.

b Calculated from $\mathrm{H}_{2}$-TPR experiments. 
recorded on 4Pt/LaFe(R300), which could suggest that the electronic properties of $\mathrm{Pt}$ are not completely restored after oxidative/reductive cycles on $4 \mathrm{Pt} / \mathrm{LaFe}(\mathrm{A500})$. Nevertheless, the most prominent information on $4 \mathrm{Pt} / \mathrm{LaFe}(\mathrm{A} 500)$ and $4 \mathrm{Pt} / \mathrm{La}-$ $\mathrm{Fe}(\mathrm{A} 500 \mathrm{R} 300)$ is probably provided by the quantitative analysis in Table 1. As indicated, it is gratifying to note only slight changes in the atomic Pt/La ratio within the margin of error, highlighting the absence of significant Pt particle sintering in agreement with TEM observations contrarily to 4Pt/Al(A500R300).

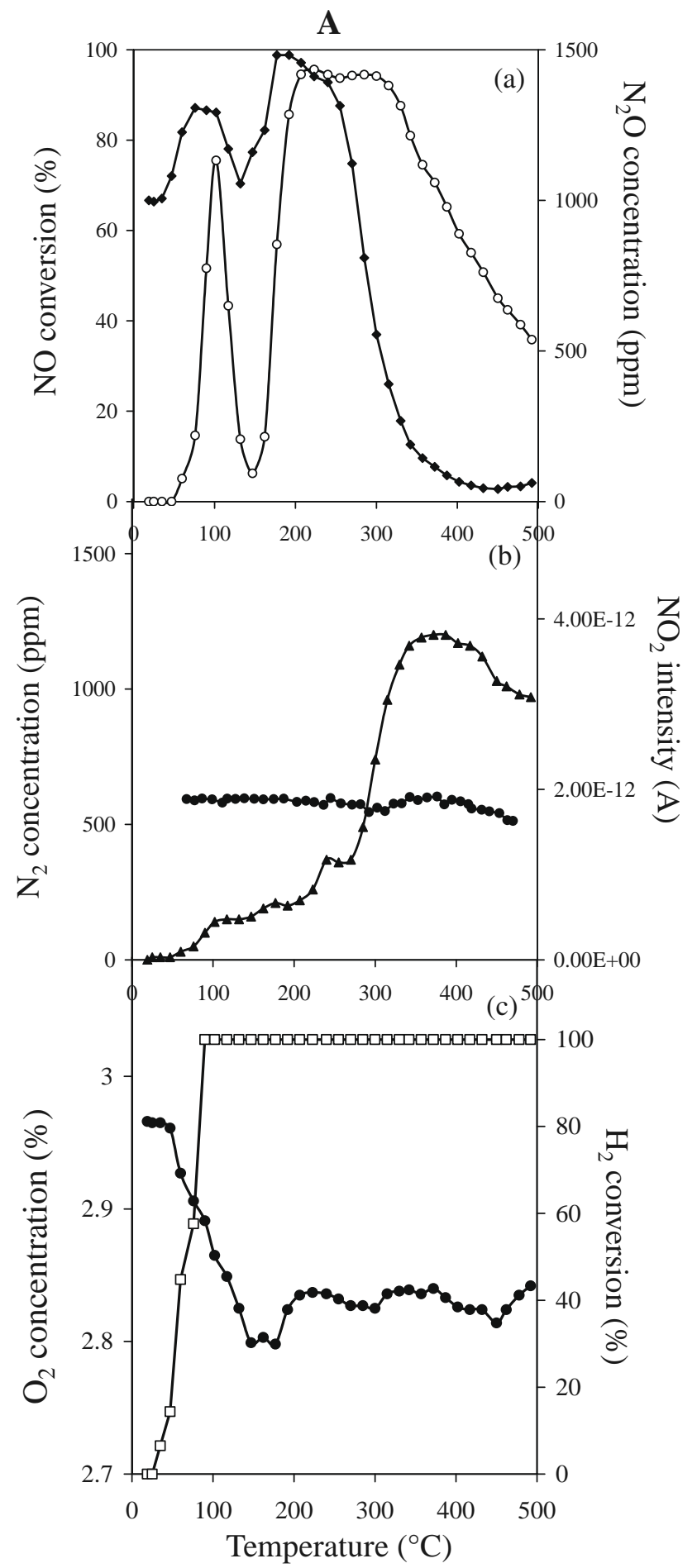

A systematic decomposition of the XPS Pt 4f 7/2 peaks was performed on $4 \mathrm{wt} . \% \mathrm{Pt} / \mathrm{LaFeO}_{3}$. Fig. 8 presents typical decomposition spectra recorded on $4 \mathrm{Pt} / \mathrm{LaFe}(\mathrm{A} 500)$ after ageing. The decomposition of the Pt $4 \mathrm{f} 7 / 2$ photopeak provides three different contributions with maxima at $71.3 \mathrm{eV}, 72.2 \mathrm{eV}$ and $74.0 \mathrm{eV}$. The former $\mathrm{BE}$ value mainly characterises metallic $\mathrm{Pt}$, whereas the latter ones would correspond to $\mathrm{Pt}^{2+}$ and $\mathrm{Pt}^{4+}$, respectively. Nevertheless, it seems obvious that the $\mathrm{BE}$ values are lower than those currently reported for $\mathrm{Pt}^{2+}(73.6-74 \mathrm{eV}[13])$ and $\mathrm{Pt}^{4+}(74.8 \mathrm{eV})$ stabilised in

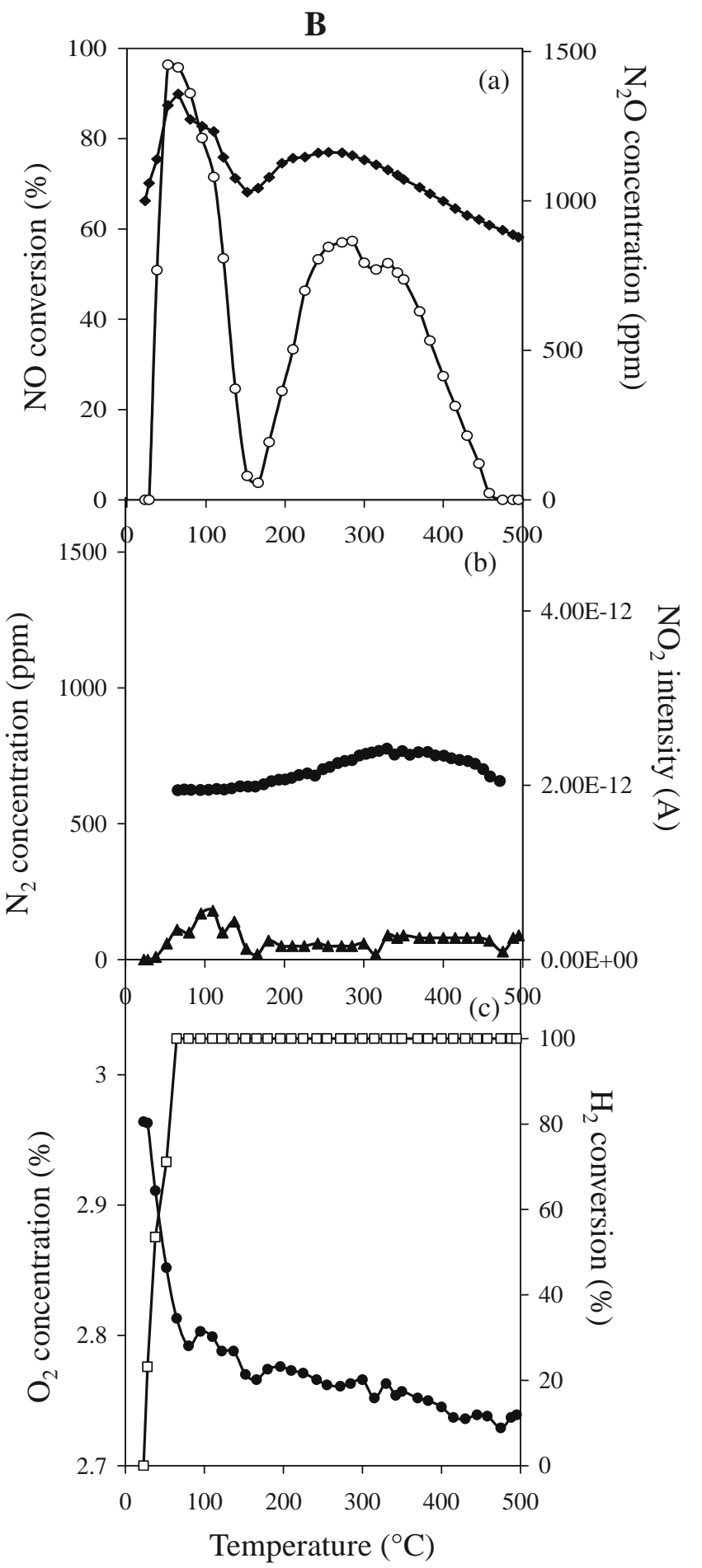

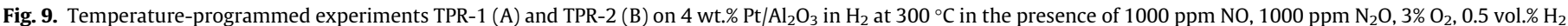

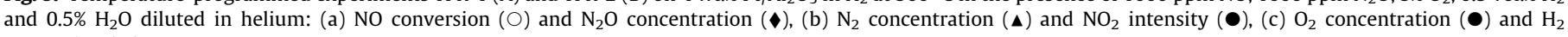
conversion ( $\square$ ). 
bulk PtO and $\mathrm{PtO}_{2}$. As previously argued, those values may also reflect the stabilisation of a $\mathrm{PtO}$ and/or $\mathrm{PtO}_{2}$ monolayer on $\mathrm{Pt}^{0}$ particles or the presence of subsurface oxygen species. Hence, these decompositions allowed us to estimate the relative amount of each Pt species at the surface according to the thermal treatment procedure in reductive or oxidative atmosphere. Results are reported in Table 2. It is interesting to note that bulk and surface compositions are quite similar on $4 \mathrm{Pt} / \mathrm{LaFe}(\mathrm{C} 400)$ with an estimate of the surface atomic $\mathrm{H} / \mathrm{Pt}$ ratio, from the relative $\mathrm{Pt}^{2+}$ and $\mathrm{Pt}^{4+}$ concentration from deconvoluted $\mathrm{Pt} 4 \mathrm{f}$ spectra, comparable to that of bulk $\mathrm{H} / \mathrm{Pt}$ value provided by $\mathrm{H}_{2}$-TPR experiments. Interestingly, no significant change seems to occur on 4Pt/LaFe(R300) and 4Pt/LaFe(A500R300), which would suggest that reversible changes would take place during successive oxidative and reductive thermal treatments. The slightly lower concentration of $\mathrm{Pt}^{4+}$ on $4 \mathrm{Pt} / \mathrm{LaFe}(\mathrm{A} 500 \mathrm{R} 300)$ seems to be in agreement with the lower $B E$ value. Regarding $4 \mathrm{Pt} / \mathrm{LaFe}(\mathrm{A} 500)$, thermal ageing under lean conditions induces a significant re-oxidation of metallic Pt particles, which could not be limited to the extreme surface accompanied with a significant increase in the $\mathrm{Pt}^{4+}$ concentration. These observations seem consistent with those provided by Hatanaka et al. on $\mathrm{Pt} / \mathrm{CeO}_{2}$ [8]. Thermodynamic calculations suggest that bulk re-oxidation of metallic Pt particle to PtO and $\mathrm{PtO}_{2}$ should be restricted at high temperature under oxidative conditions if there is no interaction between Pt and the support. In fact, these authors explained the discrepancy between predictions and experimental by the formation of strong metal/support interactions between oxidic Pt species and $\mathrm{CeO}_{2}$. Hence, the formation of a Pt-O-Ce bond would decrease the total energy of $\mathrm{Pt} / \mathrm{CeO}_{2}$ and then stabilise dispersed Pt species on the support. Similarly, stronger interactions between Pt and $\mathrm{LaFeO}_{3}$ are expected and previously characterised by epitaxially oriented Pt particles on the $\mathrm{LaFeO}_{3}$ crystal lattice. According to those explanations, the greater stabilisation of $\mathrm{Pt}^{4+}$ species on $\mathrm{Pt} /$ $\mathrm{LaFe}(\mathrm{C} 400)$ than on $\mathrm{Pt} / \mathrm{Al}(\mathrm{C} 400)$ could be also related to stronger metal/support interactions.

\subsection{Catalytic performance of $\mathrm{Pt} / \mathrm{LaFeO}_{3}$ in the simultaneous reduction of $\mathrm{NO}$ and $\mathrm{N}_{2} \mathrm{O}$ by $\mathrm{H}_{2}$}

The reduction of $\mathrm{NO}$ and $\mathrm{N}_{2} \mathrm{O}$ by $\mathrm{H}_{2}$ reaction was examined in the presence of 3 vol.\% $\mathrm{O}_{2}$ and 0.5 vol. $\% \mathrm{H}_{2} \mathrm{O}$, which are known to induce strong inhibiting effects on the reaction. The kinetic behaviour of Pt-supported catalysts may also be altered in the presence of hydrogen. Typically, the following set of target reactions yielding nitrogen can be considered [14]:

$2 \mathrm{NO}+2 \mathrm{H}_{2}=\mathrm{N}_{2}+2 \mathrm{H}_{2} \mathrm{O}$

$\mathrm{N}_{2} \mathrm{O}+\mathrm{H}_{2}=\mathrm{N}_{2}+\mathrm{H}_{2} \mathrm{O}$

Side reactions might also occur:

$$
\begin{aligned}
& 2 \mathrm{NO}+\mathrm{H}_{2}=\mathrm{N}_{2} \mathrm{O}+\mathrm{H}_{2} \mathrm{O} \\
& 2 \mathrm{NO}+5 \mathrm{H}_{2}=2 \mathrm{NH}_{3}+2 \mathrm{H}_{2} \mathrm{O} \\
& 2 \mathrm{NO}+\mathrm{O}_{2}=2 \mathrm{NO}_{2} \\
& 2 \mathrm{H}_{2}+\mathrm{O}_{2}=2 \mathrm{H}_{2} \mathrm{O}
\end{aligned}
$$

Generally, noble metals [15], particularly Pt, are recognised as none selective with reaction (6) promoted at the expense of reaction (1). At low NO conversion regime, incomplete NO reduction yielding $\mathrm{N}_{2} \mathrm{O}$ according to reaction (3) might occur. Additional competitive oxidative reactions might also take place such as the catalytic oxidation of $\mathrm{NO}$ to $\mathrm{NO}_{2}$, which usually leads to the subsequent stabilisation of nitrate species on the support [5,6]. Previous investigations also suggested the involvement of gaseous oxygen in the overall reduction of $\mathrm{NO}$ to nitrogen on $\mathrm{Pt} / \mathrm{MgO}-\mathrm{CeO}_{2}$ [16] and $\mathrm{Pt} / \mathrm{LaCeMnO}_{3}[17,18]$ according to Eqs. (7) and (8),
$2 \mathrm{NO}+4 \mathrm{H}_{2}+\mathrm{O}_{2}=\mathrm{N}_{2}+4 \mathrm{H}_{2} \mathrm{O}$

$2 \mathrm{NO}+3 \mathrm{H}_{2}+\mathrm{O}_{2}=\mathrm{N}_{2} \mathrm{O}+3 \mathrm{H}_{2} \mathrm{O}$

which suggest the participation of ad- $\mathrm{NO}_{x}$ species stabilised on the support as possible intermediates in the reduction of NO to nitrogen.

Catalytic measurements were performed on pre-reduced supported Pt catalysts on $\gamma-\mathrm{Al}_{2} \mathrm{O}_{3}$ and $\mathrm{LaFeO}_{3}$ in pure $\mathrm{H}_{2}$ at $300{ }^{\circ} \mathrm{C}$. The procedure described in Fig. 1 was implemented for the evaluation of the catalytic performances. As explained, TPR-1 and TPR-2 were performed, respectively, on as-prepared and aged catalysts

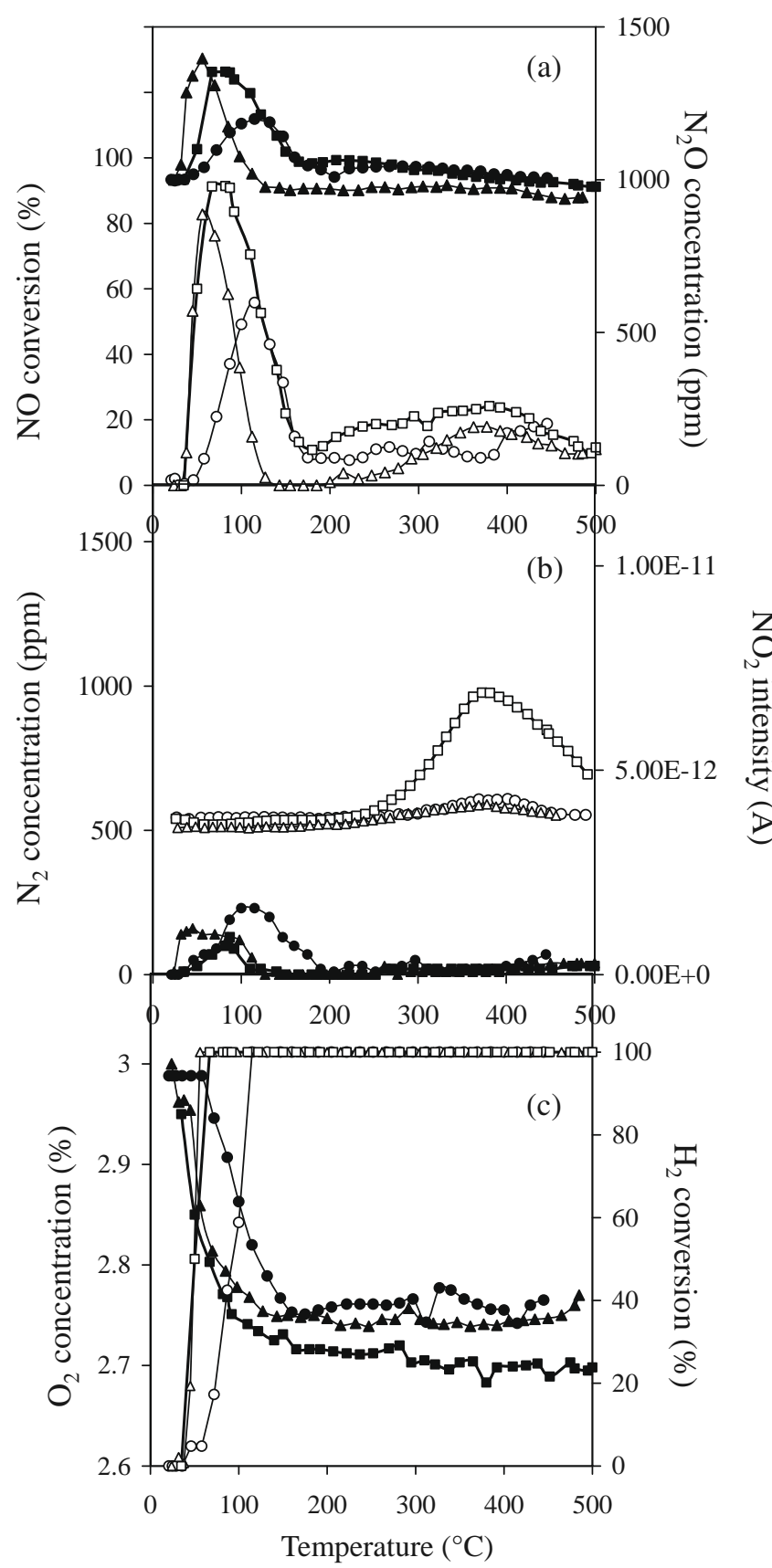

Fig. 10. Temperature-programmed experiments TPR-1 (circle), TPR-2 (triangle) and TPR-3 (square) on $4 \mathrm{wt} . \% \mathrm{Pt} / \mathrm{LaFeO}_{3}$ in the presence of $1000 \mathrm{ppm} \mathrm{NO}, 1000 \mathrm{ppm}$ $\mathrm{N}_{2} \mathrm{O}, 3 \% \mathrm{O}_{2}, 0.5$ vol. $\% \mathrm{H}_{2}$ and $0.5 \% \mathrm{H}_{2} \mathrm{O}$ diluted in helium: (a) NO conversion (blanksymbol) and $\mathrm{N}_{2} \mathrm{O}$ concentration (full-symbol), (b) $\mathrm{N}_{2}$ concentration (full-symbol) and $\mathrm{NO}_{2}$ intensity (blank symbol), (c) $\mathrm{O}_{2}$ concentration (full-symbol) and $\mathrm{H}_{2}$ conversion (blank symbol). 
previously reduced in $\mathrm{H}_{2}$ at $300{ }^{\circ} \mathrm{C}$ prior to temperature-programmed reactions. TPR experiments were also repeated on aged catalysts without any reductive post-treatment in $\mathrm{H}_{2}$ (TPR-3). TPR conversion curves recorded on $4 \mathrm{wt} . \% \mathrm{Pt} / \mathrm{Al}_{2} \mathrm{O}_{3}$ and on $4 \mathrm{wt} . \%$ $\mathrm{Pt} / \mathrm{LaFeO}_{3}$ are reported in Figs. 9 and 10, respectively. In all cases, no significant ammonia formation was observed. Similar results have already been observed in the presence of an excess of oxygen and are related to the usual strong $\mathrm{O}_{2}$ adsorption over noble metals with usual high chemisorbed $\mathrm{O}$ coverage and higher relative rates of steps associated to the formation of water between $\mathrm{H}_{2}$ and chemisorbed $\mathrm{O}$ atoms [19]. As illustrated in Fig. 9A(a), two NO conversion ranges arise on $4 \mathrm{Pt} / \mathrm{Al}(\mathrm{R} 300)$. A narrow conversion range at low temperature with a maximum NO conversion of approximately $78 \%$ leads to the preferential formation of $\mathrm{N}_{2} \mathrm{O}$ according to reaction (3), whereas the simultaneous reduction of $\mathrm{NO}$ and $\mathrm{N}_{2} \mathrm{O}$ into nitrogen takes place above $380^{\circ} \mathrm{C}$. Let us mention that the formation of $\mathrm{NO}_{2}$ has not been detected on $4 \mathrm{Pt} / \mathrm{Al}(\mathrm{R} 300)$. Different behaviour characterises $4 \mathrm{Pt} / \mathrm{Al}(\mathrm{A} 500 \mathrm{R} 300)$ as illustrated in Fig. 9B. Catalytic features are summarised in Table 3. As observed, noticeable changes take place at high temperature showing the detrimental effect of a thermal ageing in the simultaneous reduction of $\mathrm{N}_{2} \mathrm{O}$ into nitrogen. Changes in the selectivity behaviour are also observed and linked with an extra conversion of oxygen correlated to the production of $\mathrm{NO}_{2}$. Surprisingly, the low temperature NO conversion broadens with conversion starting at lower temperature and a maximum NO conversion of $95 \%$ below $100{ }^{\circ} \mathrm{C}$. It is remarkable that this gain in NO conversion is not accompanied with correlative enhancement in nitrogen production, as shown in Table 3.

Catalytic performances recorded on $4 \mathrm{Pt} / \mathrm{LaFe}(\mathrm{R} 300)$ (TPR-1), 4Pt/LaFe(A500) (TPR-3) and 4Pt/LaFe(A500R300) (TPR-2) are reported in Fig. 10. Clearly, those catalysts are less active than $4 \mathrm{wt} . \% \mathrm{Pt} / \mathrm{Al}_{2} \mathrm{O}_{3}$ irrespective of the thermal treatment particularly at low temperature. This tendency is probably due to lower Pt dispersion on perovskite, with the coexistence of small and large Pt particles, this support material exhibiting specific surface area four times lower than that of $\gamma-\mathrm{Al}_{2} \mathrm{O}_{3}$. Now, the relative comparison of NO conversion profiles on 4Pt/LaFe(R300) and 4Pt/LaFe(A500R300) shows the same tendency with a rate enhancement of NO conversion at low temperature after ageing. Nevertheless, the high temperature NO conversion range does not seem to be altered and is not accompanied with changes of the selectivity in favour of the formation of $\mathrm{NO}_{2}$ on $4 \mathrm{Pt} / \mathrm{LaFe}(\mathrm{A} 500 \mathrm{R} 300)$ contrarily to $4 \mathrm{Pt} /$ $\mathrm{Al}(\mathrm{A500R} 300)$. As a matter of fact, the more significant changes are noticeable on 4Pt/LaFe(A500) from TPR-3. As seen in Fig. 10a, a broader low-temperature conversion range is observable with a maximum conversion exceeding those previously obtained on $4 \mathrm{Pt} / \mathrm{LaFe}(\mathrm{R} 300)$ and $4 \mathrm{Pt} / \mathrm{LaFe}(\mathrm{A} 500 \mathrm{R} 300$ ) (91\% vs. 56\% and $82 \%$,

Table 3

Catalytic performance of $\mathrm{Pt} / \mathrm{Al}_{2} \mathrm{O}_{3}$ and $\mathrm{Pt} / \mathrm{LaFeO}_{3}$ at low temperature for the $\mathrm{NO}$ reduction by $\mathrm{H}_{2}$ to $\mathrm{N}_{2}$ and $\mathrm{N}_{2} \mathrm{O}$.

\begin{tabular}{lrllrrl}
\hline Catalyst & \multicolumn{1}{l}{$\begin{array}{l}\left.{ }^{\circ} \mathrm{C}\right) \\
(\%)\end{array}$} & $\begin{array}{l}X_{\mathrm{NO}} \\
(\%)\end{array}$ & $\begin{array}{l}S_{\mathrm{N}_{2}} \\
(\%)\end{array}$ & $\begin{array}{c}T_{\mathrm{M}}{ }^{\mathrm{a}} \\
\left({ }^{\circ} \mathrm{C}\right)\end{array}$ & $\begin{array}{l}X_{\mathrm{NO}}{ }^{\mathrm{b}} \\
(\%)\end{array}$ & $\begin{array}{l}S_{\mathrm{N}_{2}}{ }^{\mathrm{c}} \\
(\%)\end{array}$ \\
\hline 4Pt/Al(R300) & 90 & 52 & 25 & 102 & 75 & 25.9 \\
4Pt/Al(A500R300) & 38 & 51 & 0 & 65 & 95 & 23.5 \\
4Pt/LaFe(R300) & 100 & 49 & 55.7 & 115 & 56 & 53.7 \\
4Pt/LaFe(A500) & 50 & 60 & - & 67 & 91 & 16.5 \\
4Pt/LaFe(A500R300) & 45 & 53 & 29.2 & 56 & 82 & 28.8 \\
0.5Pt/LaFe(R300) & 120 & 47 & 31.9 & 147 & 87 & 36.9 \\
0.5Pt/LaFe(A500) & 120 & 31 & 34.2 & 147 & 89 & 34.3 \\
0.5Pt/ & 129 & 28 & 57 & 155 & 100 & 40.3 \\
$\quad$ LaFe(A500R300) & & & & & & \\
\hline
\end{tabular}

\footnotetext{
a Temperature at the maximum NO conversion.

b Maximum NO conversion.

c Selectivity at the maximum NO conversion.
}

respectively). On the other hand, a detrimental effect on the selectivity to the formation of nitrogen is remarkable as seen in Table 3. Moreover, the formation of $\mathrm{NO}_{2}$ intensifies above $300{ }^{\circ} \mathrm{C}$. All those observations underline the beneficial effect of the post-reductive thermal treatment after ageing and the poorest selectivity of $4 \mathrm{Pt} /$ $\mathrm{LaFe}(\mathrm{A} 500)$ towards to formation of $\mathrm{N}_{2}$ being presumably associated with the greater amount of $\mathrm{Pt}^{4+}$ formation at the surface. This

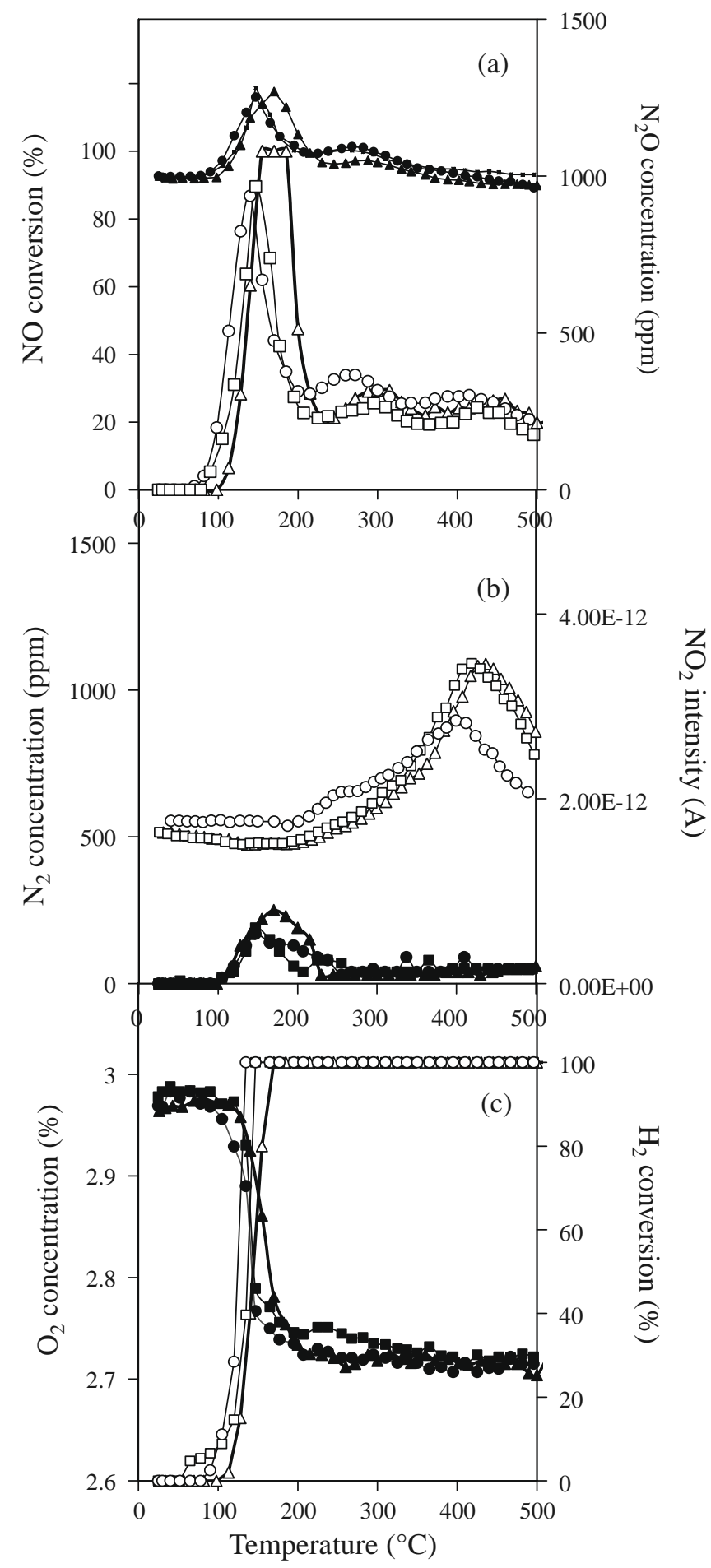

Fig. 11. Temperature-programmed experiments on $0.5 \mathrm{wt} . \% \mathrm{Pt} / \mathrm{LaFeO}_{3}$ : (TPR-1) (circle), (TPR-2) (triangle), TPR-3 (square) in the presence of $1000 \mathrm{ppm} \mathrm{NO}$, $1000 \mathrm{ppm} \mathrm{N}_{2} \mathrm{O}, 3 \% \mathrm{O}_{2}, 0.5 \mathrm{vol} . \% \mathrm{H}_{2}$ and $0.5 \% \mathrm{H}_{2} \mathrm{O}$ diluted in helium: (a) NO conversion (O) and $\mathrm{N}_{2} \mathrm{O}$ concentration ( $\bullet$ ), (b) $\mathrm{N}_{2}$ concentration ( $\mathbf{\Delta}$ ) and $\mathrm{NO}_{2}$ intensity $(\bullet)$, (c) $\mathrm{O}_{2}$ concentration $(\bullet)$ and $\mathrm{H}_{2}$ conversion ( $\square$ ). 
is clearly illustrated in Table 3, with significant enhancement in $\mathrm{N}_{2}$ production on $4 \mathrm{Pt} / \mathrm{LaFe}(\mathrm{A500R} 300)$ in comparison with $4 \mathrm{Pt} /$ $\mathrm{LaFe}(\mathrm{A500})$.

In the light of those observations, the stabilisation of the dispersion of noble metals over perovskite-based materials offers new perspectives with the opportunity to lessen noble metal loadings without altering the number of accessible sites because of a strong attenuation of thermal sintering processes. In order to verify such a hypothesis, the catalytic performance of $0.5 \mathrm{wt} . \% \mathrm{Pt} / \mathrm{LaFeO}_{3}$ has been examined. Additional bulk and surface characterisation of as-prepared and aged catalysts from $\mathrm{H}_{2}$-TPR and XPS experiments agree with previous tendencies reported on $4 \mathrm{wt} . \% \mathrm{Pt} / \mathrm{LaFeO}_{3}$ showing a more accentuated stabilisation of well-dispersed Pt species on $\mathrm{LaFeO}_{3}$ than on alumina. As seen in Table 1, a slight increase in the atomic $\mathrm{H} / \mathrm{Pt}$ suggests a greater stabilisation of $\mathrm{Pt}^{4+}$ species on $0.5 \mathrm{Pt} / \mathrm{LaFeO}_{3}(\mathrm{C} 400)$ than on $4 \mathrm{Pt} / \mathrm{LaFe}(\mathrm{C} 400)$, which might reflect more extensive metal/support interactions as earlier discussed. Such an explanation is supported by XPS measurements based on the comparison of the atomic Pt/La ratios. As exemplified in Table 2 , the relative decrease in the Pt/La values with respect to the calcined precursors $(0.5$ and $4 \mathrm{Pt} / \mathrm{LaFe}(\mathrm{C} 400))$ attenuates on $0.5 \mathrm{wt} . \%$ $\mathrm{Pt} / \mathrm{LaFeO}_{3}$ ( $16 \%$ vs. $27 \%$ on $4 \mathrm{wt} . \% \mathrm{Pt} / \mathrm{LaFeO}_{3}$ ), which reflects a greater stabilisation of well-dispersed Pt particles.

Temperature-programmed conversion and concentration curves vs. temperature are reported in Fig. 11 on $0.5 \mathrm{Pt} / \mathrm{LaFe}(\mathrm{R} 300)$ (TPR-1), 0.5Pt/LaFe(A500) (TPR-2) and 0.5Pt/LaFe(A500R300) (TPR$3)$. Interestingly, the $\mathrm{NO} / \mathrm{H}_{2}$ reaction takes place in a broader lowtemperature range than on $4 \mathrm{Pt} / \mathrm{LaFe}(\mathrm{R} 300)$ with a maximum NO conversion of approximately $90 \%$. On the other hand, the formation of $\mathrm{NO}_{2}$ is promoted at higher temperature contrarily to highly loaded Pt catalysts. As seen, thermal ageing has a beneficial effect on the conversion of NO on $0.5 \mathrm{Pt} / \mathrm{LaFe}(\mathrm{A} 500 \mathrm{R} 300)$ at low temperature with an enlargement of the operating window and a complete conversion of $\mathrm{NO}$ into $\mathrm{N}_{2}$ and $\mathrm{N}_{2} \mathrm{O}$. However, the most remarkable observation is probably related to the significant enhancement in $\mathrm{N}_{2}$ selectivity on $0.5 \mathrm{Pt} / \mathrm{LaFe}\left(\mathrm{A500R300}\right.$ ) with $\mathrm{N}_{2}$ production higher than that recorded on $0.5 \mathrm{Pt} / \mathrm{LaFe}(\mathrm{R} 300)$. In parallel, no extra $\mathrm{NO}_{2}$ formation is observable in comparison with $4 \mathrm{Pt}$ / $\mathrm{LaFe}(\mathrm{R} 300)$. All those observations emphasise the fact that the thermal-ageing process does not affect the selective transformation of NO to nitrogen at low temperature. Hence, regarding those results, it seems obvious that substantial lowering of noble metals loading is possible and may lead to a greater extent of activity because of stronger metal/support interactions, which would preserve the metallic character of Pt. Those results are consistent with previous investigations with the occurrence of two different mechanisms for the production of $\mathrm{N}_{2}$ and $\mathrm{N}_{2} \mathrm{O}$. Let us mention that the formation of $\mathrm{NO}_{2}$ has already been reported in a wider temperature range $[15,20]$. Mac Leod and Lambert $[20]$ argued that the $\mathrm{NO} / \mathrm{H}_{2}$ reaction is governed by the competition between $\mathrm{NO}$ and $\mathrm{O}_{2}$ for adsorption on noble metals, which becomes in favour of oxygen with a rise in temperature. Ueda et al. [15] also concluded that the $\mathrm{NO} / \mathrm{H}_{2}$ reaction goes through the in situ generation of $\mathrm{NO}_{2}$ at high temperature but without decisive arguments because they found that the $\mathrm{O}_{2} / \mathrm{H}_{2}$ reaction predominates at the expense of the $\mathrm{NO}_{2} / \mathrm{H}_{2}$ reaction. Despite numerous investigations dedicated to the $\mathrm{NO} / \mathrm{H}_{2}$ reaction, there are still controversial statements related to the mechanisms and the nature of the active sites. Hence, the low NO conversion range is usually assigned to the presence of metallic noble metals when they are dispersed over inert materials, such as alumina [15,19]. Previous explanations suggest that subsequent increase in temperature would lead to the loss of the metallic character of noble metals and correlatively to changes of the selectivity to the production of $\mathrm{NO}_{2}$. Our observations on 4Pt/ $\mathrm{LaFe}(\mathrm{A} 500)$ associated with partial oxidation of $\mathrm{Pt} \mathrm{Pt}^{4+}$ are consistent with the preferential production of $\mathrm{N}_{2} \mathrm{O}$ and $\mathrm{NO}_{2}$, respec- tively, at low and high temperature, which can be associated with a slower NO dissociation than on $4 \mathrm{Pt} / \mathrm{LaFe}(\mathrm{R} 300)$ and $4 \mathrm{Pt} / \mathrm{La}-$ $\mathrm{Fe}(\mathrm{A} 500 \mathrm{R} 300)$. The reductive post-treatment in $\mathrm{H}_{2}$ partly restores the selectivity behaviour except on 4Pt/Al(A500R300), which highlights the importance of the support. Previous investigations reported significant improvement of Pd supported on reducible supports. By way of illustration, Barrera et al. [21] characterised strong interactions between $\mathrm{Pd}$ and $\mathrm{La}_{2} \mathrm{O}_{3}$ forming $\mathrm{Pd}_{3} \mathrm{LaO}_{x}$ after reductive treatment, which promote the production of nitrogen during NO conversion. Such extensive surface reductions are not expected on $\mathrm{Pt} / \mathrm{LaFeO}_{3}$ according to $\mathrm{H}_{2}$-TPR and XPS observations, which show that $\mathrm{LaFeO}_{3}$ is not reduced after Pt impregnation, significant reduction processes being only activated at relatively low temperature when Pt is directly incorporated into the orthorhombic structure of the perovskite during the sol-gel preparation. Nevertheless, it seems to be obvious that the post-reductive treatment plays a key role in determining the catalytic properties of Pt/LaFe$\mathrm{O}_{3}$, which would affect more strongly small metallic Pt particles. This is well illustrated by the recent investigations reported by Costa and Efstathiou on Pt/LaCeMnO 3 [17,18] and Pt/MgO-CeO [16], which showed remarkable catalytic performances in the $\mathrm{NO} / \mathrm{H}_{2} / \mathrm{O}_{2}$ reactions associated to the extent of the metal/support interface. In fact, the reduction of ad- $\mathrm{NO}_{x}$ species located on the support would depend on the rate of the $\mathrm{H}$-spillover from the $\mathrm{Pt}$ surface to the vicinity of the support. These authors explained that the rate of this process would be governed by the Pt particle size and its morphology. Shibata et al. [22] envisaged modifications of the electronic properties more accentuated on smaller particles, which might alter the chemical bonding of $\mathrm{H}$ on Pt and the subsequent $\mathrm{H}$-spillover. As a matter of fact, TEM observations provide significant evidences on the existence of strong $\mathrm{Pt} / \mathrm{LaFeO}_{3}$ interactions with a preferential orientation of $\operatorname{Pt}\left(\begin{array}{lll}1 & 1 & 1\end{array}\right)$ on the characteristic crystallographic plans of the perovskite structure, which may originate synergy effects on the activity and selectivity as previously found [14]. Clearly, those structural changes induce modifications in the adsorptive properties of $\mathrm{Pt}$ preserving the accumulation of oxygen at the surface and the metallic character of Pt particularly during thermal ageing in lean conditions. This effect is essentially characterised at low temperature and more accentuated on low Pt loaded 0.5Pt/LaFe(A500R300) samples minimising the formation of Pt aggregates. As a matter of fact, this result opens the possibility to optimise the metal loading and the pre-activation thermal treatment. A striking promotion of the selective reduction of $\mathrm{NO}$ to $\mathrm{N}_{2}$, at the expense of the $\mathrm{NO}$ oxidation to $\mathrm{NO}_{2}$, in a wider range of temperature will be presented in a forthcoming paper.

\section{Conclusion}

This investigation compared the catalytic performances of $\mathrm{Pt} /$ $\mathrm{Al}_{2} \mathrm{O}_{3}$ and $\mathrm{Pt} / \mathrm{LaFeO}_{3}$ with a special attention on the impact of thermal ageing in the $\mathrm{NO} / \mathrm{H}_{2}$ reaction. It has been found that a significant loss of activity and selectivity affects the catalytic behaviour of $\mathrm{Pt} / \mathrm{Al}_{2} \mathrm{O}_{3}$ at high temperature due to thermal sintering of Pt particles. On the other hand, this process is inhibited on $\mathrm{Pt} / \mathrm{LaFeO}_{3}$. Stabilisation of the Pt dispersion on perovskite can be explained by the existence of stronger metal/support interaction under reductive atmosphere as well illustrated by the occurrence of an epitaxial growth of Pt(l 111 1) plans with the characteristics surface plans of the orthorhombic structure of $\mathrm{LaFeO}_{3}$. Such microstructures would be preserved under oxidative conditions further blocking the particle growth of Pt oxide clusters, which originates an increase in $\mathrm{NO}_{2}$ formation. Nevertheless, contrarily to $\mathrm{Pt} / \mathrm{Al}_{2} \mathrm{O}_{3}$, reversible changes occur on $\mathrm{Pt} / \mathrm{LaFeO}_{3}$ illustrated by a strong attenuation of $\mathrm{NO}_{2}$ formation. Hence, the peculiar properties of $\mathrm{LaFeO}_{3}$ 
have been profitably used for the synthesis of supported Pt catalysts containing a drastically lower amount of noble metal. As observed, a significant rate enhancement in the $\mathrm{NO} / \mathrm{H}_{2}$ reaction can be obtained, which opens new perspectives of those types of catalysts.

\section{Acknowledgments}

We gratefully acknowledge the Region Nord-Pas-de-Calais through the Institut de Recherche en Environnement Industriel and the Ademe for a PhD fellowship (J.P. Dacquin). We thank Mrs. M. Frère and Mr. O. Gardoll who conducted XPS and thermal analysis experiments, respectively.

\section{References}

[1] Y. Nishihata, J. Mizuki, T. Akao, H. Tanaka, M. Uenishi, M. Kimura, T. Okamoto N. Hamada, Nature 418 (2002) 164

[2] M. Uenishi, M. Tanigushi, H. Tanaka, M. Kimura, Y. Nishihata, J. Mizuki, T. Kobayashi, Appl. Catal. B 57 (2005) 267.

[3] H. Taguchi, S.I. Matsu-ura, M. Nagao, T. Choso, K. Kabata, J. Solid State Chem. 129 (1997) 60.

[4] M. Uenishi, H. Tanaka, M. Tanigushi, I. Tan, M. Kimura, Y. Sakamoto, S. Matsunaga, K. Yokota, T. Kobayashi, Appl. Catal. A 296 (2005) 114.
[5] I. Twagirashema, M. Engelmann-Pirez, M. Frere, L. Burylo, L. Gengembre, C. Dujardin, P. Granger, Catal. Today 119 (2007) 100.

[6] J.P. Dacquin, C. Dujardin, P. Granger, J. Catal. 253 (2008) 37.

[7] I. Twagirashema, M. Frere, L. Gengembre, C. Dujardin, P. Granger, Top. Catal. 42-43 (2007) 171.

[8] M. Hatanaka, N. Takahashi, N. Takahashi, T. Tanabe, Y. Nagai, A. Suda, H. Shinjoh, J. Catal. 266 (2009) 182.

[9] M. Engelmann-Pirez, P. Granger, G. Leclercq, Catal. Today 107/108 (2005) 315

[10] H. Tagushi, S.I. Matsu-ura, M. Nagao, T. Choso, K. Kabata, J. Solid State Chem. 129 (1997) 60.

[11] D.A. Shirley, Phys. Rev. B 5 (1972) 4709.

[12] A.S. Mamede, G. Leclercq, E. Payen, P. Granger, L. Gengembre, J. Grimblot, Surf Interface Anal. 34 (2002) 105

[13] D. Briggs, M.P. Seah, Practical Surface Analysis, second ed., vol. 1, Wiley, New York, 1983, p. 613.

[14] F. Dhainaut, S. Pietrzik, P. Granger, J. Catal. 258 (2008) 296

[15] A. Ueda, T. Nakato, M. Azuma, T. Kobayashi, Catal. Today 45 (1998) 135.

[16] C.N. Costa, A.M. Efstathiou, Appl. Catal. B 72 (2007) 240.

[17] C.N. Costa, A.M. Efstathiou, J. Phys. Chem. B 108 (2008) 2620.

[18] C.N. Costa, A.M. Efstathiou, J. Phys. Chem. C 108 (2007) 111

[19] F. Dhainaut, S. Pietrzyk, P. Granger, Top. Catal. 42-43 (2007) 135.

[20] N. Mac Leod, R.M. Lambert, Appl. Catal. B 35 (2002) 269.

[21] A. Barrera, M. Viniegra, P. Bosch, V.H. Lara, S. Fuentes, Appl. Catal. B 34 (2001) 97.

[22] J. Shibata, M. Hashimoto, K. Shimizu, H. Yoshida, T. Hattori, A. Satsuma, J. Phys. Chem. B 108 (47) (2004) 18327. 